\title{
Milorad Stojević
}

\section{KUĆNI PORNIĆI NIKOLE POLIĆA (EX LIBRIS EROTICIS BRAĆE POLIĆ)}

\author{
Izvorni znanstveni rad \\ Original scientific paper \\ UDK 821.163.42-993-1 \\ 821.163.42.09 Polić, N.
}

Ovaj rad govori o dvjema pornografskim pjesmama Nikole Polića, koje se nalaze u njegovoj ostavštini. Te se pjesme promatraju u sklopu pjesničkih Polićevih nazora i u odnosu na njegov ostali pjesnički opus.

Ključne riječi: pjesništvo N. Polića, pornografske pjesme, hrvatska poezija

Rečenica Sve je već o poeziji Nikole Polića rečeno ${ }^{1}$ kao da je „prokletstvo“ pisanja o njoj, Polićevoj poeziji, a i ona kao da uvijek ne potiče na nova tekstualna preispitivanja. Vjerojatno je uzrok tipičnost i topičnost pjesništva toga hrvatskog književnika, a i to što su o njemu rano, već početkom prošloga stoljeća, izrečene prosudbe koje su, izgleda, tako čvrste da svakako pokrivaju gotovo sve razine Polićeve pjesničke karakterističnosti. Te procjene Nikolu Polića prate i do danas pa se čini da nitko ne želi iznova popačati u njegove pjesme i o njima izreći što novo, ili možda drugačijim kritičkim aparatom argumentirati ustaljena stajališta.

Znakovito je to za tzv. prohodne poetike dopadnih „svevremenih“ pjesama, odnosno za pjesništvo koje ne krije svoje poetološko podrijetlo, štoviše - kao da to ishodište želi pokazati što više svojega corpusa i ornatusa te tako uljuljati recipijenta u vrlo zadane okvire zanata prokušane forme i „,vječnih“ tema.

Određene „nominalne ispravke“ učinio je u nekoliko navrata sâm Nikola Polić u nekim intervjuima i memoarskim zapisima. ${ }^{2} U$ njima on osporava svoju pripadnost Matoševoj školi, a i Gričanima, što je potpuno u suprotnosti s prosudbama o njegovoj poeziji. Kako bilo da bilo, poetozofski učinci uvijek se ne slažu s Polićevim nijekanjem. Nikola Polić sugerira da je njegova poetogenetska sklonost veća prema Vladimiru Vidriću,

\footnotetext{
${ }^{1}$ Milan Crnković, Poezija Nikole Polića, u: N. Polić, Pjesme, ICR, Rijeka 1991., str. 339.

${ }^{2}$ Npr.: N. Polić, „Pro domo. Genealogija jedne, u ovom slučaju - moje lirike“, Republika 6/1953., str. 510-519.
} 
Đuri Jakšiću i S. S. Kranjčeviću, pa su to neki proučavatelji njegove poezije tek dijelom prihvatili, M. Crnković primjerice ${ }^{3}$, a neki su, kao Ljubo Wiesner ${ }^{4}$, i prije anticipirali to pjesnikovo stajalište o vlastitim pjesničkim korijenima. U novije doba s uvažavanjem se prihvaćaju Polićeve poetogenetske reminiscencije u Cvjetka Milanje ${ }^{5}$.

Pjesnikova sugestija vrijedi tek ako Polićevu poeziju promatramo u širem receptivnom lancu ukusa njegova pjesničkog kružoka, koji Hijacint Petris u pogovoru Polićevih Pjesama naziva čudnovatom svitom „koju su sačinjavali probisvijeti, zaludnici, zgubidani, vjetropiri, pastorčad, propali đaci, divljaci građanskog društva na prelomu, a u književnosti pseudotrubaduri, pozeri, anarhoindividualisti i futuristi“ ${ }^{\prime 6}$. No svita je više dotaknuta novosimbolizmom negoli recentnim im avangardnim hrvatskim i europskim pjesničkim kretanjima.

Ukratko, poeziju Nikole Polića prati desetak kritičkih toposa, između kojih se inzistentnije perpetuiraju ovi loci communes: urbani pjesnik, gradski štimung i raspoloženja u pejzažu, pjesnik interijera i eksterijera, klavirska lirika, lirika glazbe, glazbena lirika, skladnost forme tj. vjernost čistoći i uglađenosti forme, artizam, pejzažnost, usamljenost/ osamljenost, pjesništvo malih stvari i malih ljudi, tamne i bolne slike i sl. Nikola Polić nije ostavio velike i nove poetološke tragove, ali je razvidno da je baštinio neposredno mu prethodne i neposredno mu recentne literarnosne pjesničke tragove bolje negoli mu mnogi suvremenici.

Njegova poezija ne pruža poetološki otpor u interpretativnosti. S tim u vezi, ona je i predmetnotematski i izričajno poetološki ziheraška, ali su ziheraške osnove obvijene postojanim ornatusom, ta je poezija provjerena, uhodana, gdjekada rutinerskoga artizma, unutar kojega se odmah razaznaju metametrički odnosi. Jednostavnije: to je poezija koja ne krije ništa bitno poetološki, jer joj to i je nakana, pa se kadšto doima reproduktivnim modelom s namjerom da se šablona neznatno individualizira tek radi „nužne“ poetske identifikacije.

Bez obzira na inzistentnost kritičkih mjesta o poeziji Nikole Polića - što bi značilo da se interpretativnost recipijenata iscrpila već na početku, te odredila na određen način i aksiološku poziciju toga autora - razvidno je ipak da je N. Polić miljenik hrvatskih pjesničkih antologija i panorama XX. stoljeća, počevši od glasovite Hrvatske mlade lirike iz 1914. godine pa do suvremenih pjesničkih inventura.

\footnotetext{
${ }^{3}$ Ibid.

${ }^{4}$ Lj. Wiesner, u: N. Polić, Jučerašnji grad (Predgovor), Društvo mladih književnika, Zagreb 1936.; M. Crnković, o. c.

${ }^{5}$ C. Milanja, Hrvatsko pjesništvo 1900. - 1950. Novosimbolizam. Dijalektalno pjesništvo, Jerkić tiskara, Zagreb 2008., str. 84-96.

${ }^{6}$ H. Petris, Nikola Polić, u: N. Polić, Pjesme, Zora, Zagreb 1951., str. 153-160; usp. M. Crnković, o. c., str. 340.
} 
Unutar te, prvovrsno izričajne, prohodnosti, u rukopisnoj ostavštini ${ }^{7}$ Nikole Polića na predmetnotematskoj razini ističu se dvije njegove, neobjavljene, onanističke (pornografske?) pjesme: Kurčev monolog ${ }^{8}$ i Sveti Alojzije pred Madonom ${ }^{9}$. Glase one ovako:

\section{Kurčev monolog}

Moj Preradov je putnik zabludio u šumi,

Ko neposlušna djeca dva jajca klopoću mi:

Klap, klap, klap,

Prodire moj štap!

Al ne brije me sjever, što više, toplo tu je

I u tišini mokroj moj propeler ruje:

Klip, klip, klip,

Samo jedan hip!

Al onda nasta juriš, panika i strava

I kao Marseljeza crveni se glava:

Klop, klop, klop

Pucam kao top!

I k suncu letio je Ikar, svladao nebo,

I srušio se najzad: previše je jebo:

Klup, klup, klup

Potreso se stup!

Izadjoh tad iz šume. Jajca klopoću mi

I kao tužna jeka stara pjesma šumi:

Klep, klep, klep,

Podvio sam rep!

S. 17. II. 920.

\footnotetext{
${ }^{7}$ Ostavština Nikole Polića i njegova brata Janka čuva se u Narodnoj knjižnici i čitaonici u Selcu kraj Crikvenice. Darovao ju je dr. Vinko Antić.

${ }^{8}$ Napisana je tintom na požutjelom i više puta presavijanom papiru veličine $25 \times 10 \mathrm{~cm}$.

${ }^{9}$ Napisana tintom na požutjelom papiru, također više puta presavijanom, veličine $16 \times 10,5 \mathrm{~cm}$.
} 


\section{Sveti Alojzije pred Madonom}

„Moje su patnje onanije Moj kurac ko molitva zvoni. I steže se sve polaganije I umire po šabloni.“

Tako Alojzije Madoni Sav znojan šalje litanije. Svoj klimaks on desnicom goni I mliječna kap već vani je.

I rujni se ljiljan već prignuo I zgrčio poput puža.

Alojzije je pogled uzdignuo

I sav blijed ko uvenula ruža Tad pošo je iz šekreta Još danas zamišljen šeta.

\section{S. 17. II. 920.}

Vjerojatno je takvih pjesmica bilo više, ili je Nikola Polić, ili su braća Polić (Milutin,

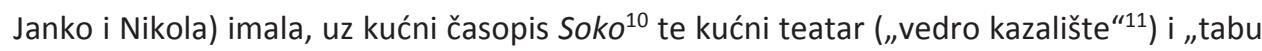
knjižnicu“ erotsko-pornografske provenijencije, jer se u ostavštini (u selačkoj knjižnici) nalazi i znak te, zasad nepoznate, knjižnice, a pod nazivom EX LIBRIS EROTICIS s upečatljivo narisanim znakom i rukom pisanim nazivom knjiškog erotikona.

Znak je vaza s „biljkom-cvijetom“. Vaza u sredini ima tri netipična položaja iz figurae veneris uokvirenih, iznad figura i ispod njih, ornamentima trokuta i ukošenih kvadrata. Dno vaze ističe se neutralnim vijugama a njezin vrh obrubljen je s pet malih falusa i pridodanim testisima. „Biljka-cvijet“ umjesto listova ima izokrenute penise, a cvjetovi su na njima - muda i falusne dlake.

10 Potpisivao se tamo kao N. P. Pećinski, a predstavio se u Sokolu s nekoliko pričica. Imao je tada devet godina. Obiteljski časopis „izlazio“ je 1899. godine, u jednom rukom pisanom primjerku i u nekoliko brojeva, a uređivali su ga Milutin (pod imenom Jadran Kvarnerski) i Janko Polić (kao Vojmir Trsatski).

${ }^{11}$ Usp. N. Polić, Iskopine, u: J. P. Kamov, Pjesme, novele i lakrdije, ICR, Rijeka 2000., str. 9-10. 
Okomito prema tekstu pjesme Sveti Alojzije pred Madonom napisana je „čvršće“ i čini se naknadno dodana posveta, ili podsjetnik za dar - Za Mirkeca. Najvjerojatnije se to odnosi na Mirka Uzorinca, slikara i karikaturista koji je, između ostaloga, 1921. godine po sjećanju uljem na platnu naslikao Nikolina brata Janka Polića Kamova i nacrtao dvije njegove studije, koje su zacijelo prethodile slici u ulju.

Prije erotografske raščlambe dviju pjesama Nikole Polića valja reći da erotsko i žensko nije nazočno u njegovim stihovima. Pa i kada se o tome nategnuto sluti, predmetnotematski kôd „bježi“ ili u rasplinutu višeznačnost ili u koji „čvršći“ motiv ili temu. Stoga erotsko nije markirano ni kao pritajena poetska predmetnotematska nakana, zamagljen fon ni njegov detalj. Nikola Polić nikako nije u svojim tekstovima, navlastito pjesničkim, posvećivao pozornost erotičkim i sličnim temama, još manje pornosu.

O ženama i odnosu prema vlastitoj tjelesnosti naznačio je ponešto u tekstu Sjećanja i zbivanja. Drugi boravak u Zagrebu (1920-1922) ${ }^{12}$. Tamo o ženama kaže: U odnosu prema ženama proživljavah gladne dane i besnene noći, ali bez putenih (plotnih) uzrujavanja i bez polucija. Nenahranjenom bio mi je bliži obilan objed od zavodljive žene. To još ne znači da izbjegavah žensko društvo; naprotiv, one izbjegavahu moje, jer sam neprivlačiv i nezanimljiv. Malo se koja nije dosađivala u mojem društvu. ${ }^{13}$ Tome dojmu Polić suprotstavlja odnos trubadurskih putova, kako je napisao, Domjanićevog botaničkog erotskog vrta ${ }^{14}$, posuta ciklamama i glicinijama, naspram stihova što ih je, tobože, naš pjesnik preferirao, a koji bijahu okruženi birtaškim rimama prokletog pjesnika $F$. $V_{\text {Villona }}{ }^{15}$. Glede francuskog pjesnika-obješenjaka Françoisa Villona, Nikicu Polića prati ili zaborav ili želja za korekcijom stranih mu duhovnih poticaja, ne i pjesničkih. Naime, šest godina prije tog izjašnjavanja u kome Villona spominje kao uzornu opreku botanički i poetički galantnom Dragutinu Domjaniću, naš pjesnik priznaje u tekstu Pro domo ${ }^{16}$ ovo: Na mene su jači 'prijevodni' dojam ostavili prijevodi Villonovih balada u 'Hrv. kolu' br. 7-8 (1952) od nepoznatog prevodioca V. $R .{ }^{17}$ Bit će stoga, ipak, da je naš autor više mirisao domaće ciklame i glicinije, negoli Francuzove nekad i eksplicitne erotske naznake, ali ga nisu ostavljale ravnodušnima.

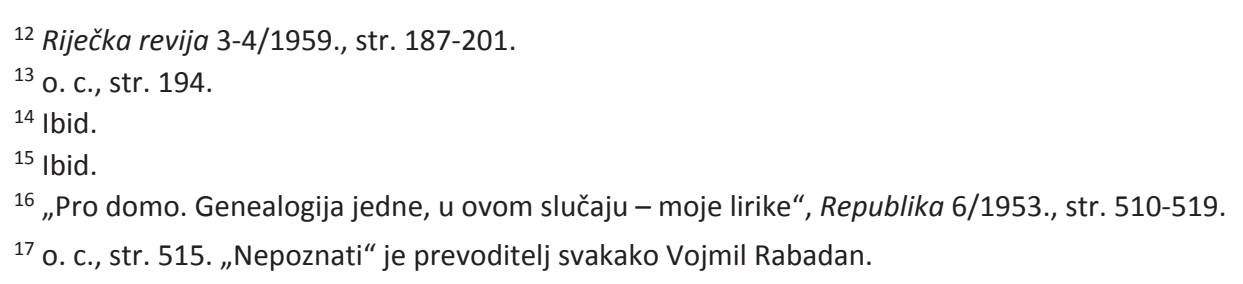


Obje erotične sorte, Domjanićevu i Villonovu, Nikola Polić svodi pod nadzemaljsku i astralnu erotiku ${ }^{18}$, a sâm odabire drugačiji put: put-do javne kuće, pa, dok me onaj prvi put, trubadurski, ostavio bez posljedica, ovaj me drugi, ovozemni, udario žigom - kao nekom vizom doživotnog liječenja injekcijama putem - socijalnog osiguranja.

S trubadurskog puta osta mi samo jedno sjećanje: jedna žena, koju i danas gledam, mada razgovarasmo svega tri puta u životu.

Sa drugog, ovozemnog puta, osta mi, osim injekcija i pun pretinac jalove prepiske i slomljeni palac desne ruke, jer me jedne pijane noći ljubomorni muž gurnuo niz trsatsku strminu. ${ }^{19}$

Potom Nikola Polić prelazi na erotičnu literaturu, kojom 1957. godine osvježava sjećanja na žene od 1908. do 1920. Od zanimljivih mu autora spominje Davida Herberta Lawrencea i E. Zolu. „Raščlanjujući“ u desetak redaka glasoviti Lawrenceov roman Duga ${ }^{20}$, Nikola Polić spominje i pornografiju. On ju shvaća ovako: Sve se te ljubavi odvijaju na terenu najprimarnije putenosti, počinju nedužnim cjelivanjem, a nakon opasnih i zavodljivih varijacija na istu temu završavaju apoteozom: on gura jezik u njezina usta. // ne protivim se ovim uzbudljivim detaljima, volim zabranjenu literaturu kao i duhovitu pornografiju, iako ona znači često i lasfemiju, samo ako nije dosadna! $!^{21}$

Moglo bi se iz toga iščitati da je Nikolu Polića pornografija zanimala, barem 10. listopada 1957., kada je svršio ${ }^{22}$, kako je naveo na kraju, tekst s naslovom Sjećanja i zbivanja.

Kurčev monolog i Sveti Alojzije pred Madonom na predmetnotematskoj razini blago su pornografske pjesme, s užom specifikacijom da su one sadržajno muške i nedvojbeno pod okriljem biblijskog Onana, sina Judina iz Knjige Postanja ${ }^{23}$. One su predmetnotematski masturbantske, samozadovoljavajuće, doduše maldororske samo u osnovnom, i globalnom, određenju ${ }^{24}$.

\footnotetext{
${ }^{18}$ Sjećanja i zbivanja, str. 194.

$19 \mathrm{lbid}$.

${ }^{20}$ Referencije na Dugu zasigurno se ne odnose na dvadesete godine XX. st. kojih se N. Polić sjeća. Naime, Lawrenceov roman pojavio se 1915. g. kada je pod optužbom opscenosti zabranjen, a primjerci su zaplijenjeni i spaljeni. Pojavljuje se na tržištu tek 11 godina poslije. Na hrvatski ga je 1957. preveo Zlatko Gorjan pa je Dugu Polić vjerojatno tada čitao.

${ }^{21}$ Sjećanja i zbivanja, ibid.

22 o. c., str. 201.

${ }^{23}$ Post 38,4.8-9; 46,12; Br. 26,19.

${ }^{24} \mathrm{Mal} d^{\prime}$ aurore, jutarnji porok, jutarnje zlo, tj. onanija, otuda ime Lautréamontova junaka u Pjevanjima.
} 
Ta se stratifikacija može tumačiti na više načina. Gledano sa sociotematskog fona to su pjesme grabancijaškog, boemskog, muškog kavanskog miljea, onog samozadovoljavajućeg na razini cigarete, kave, žestice i vina, i, dakako, onanije i snova povezanih s njom. Čudno je, ipak, kako ti snovi nisu dirnuli poetološke osnove Nikole Polića, pa i u dalekim mikrostrukturama, pogotovo što se u više navrata pozivao na trubadurske pouke. Dakle te su dvije pjesme bile namijenjene za uveseljavanje ne samo slikaru Uzorincu nego cijeloj „čudnovatoj sviti“ o kojoj piše H. Petris ${ }^{25}$.

Mogu se u intonacije te dvije „šporke“ pjesme usporediti s nekima koje su nastale približno u isto vrijeme kada i Kurčev monolog i Sveti Alojzije pred Madonom. Šporkarije su nastale, najvjerojatnije pukim slučajem, u S. ${ }^{26}$, 17. II. 1920., na 55. obljetnicu Kranjčevićeva rođenja. Šporkopisni se stihovi formom i izražajnijom aktualijom mogu usporediti s posthumno objavljenim pjesmama Sušak, Sonet s repom i Jao! Jao! ${ }^{27}$, koje su potpisane s Fra Carlo, a napisane su 12. III. 1920. Doima se kao da su bile napisane ili za neki satirični prilog ili za grabancijašku svitu, jer se osjeća određeni politički prosvjed i neskrivena ojađenost aktualnim političkim zbivanjima u Sušaku i Rijecier.

$U$ vezi s dvjema onanističkim pjesmama razvidan je intelektualni, odnosno kulturološki i literarnosni fon. Tako se penis u Kurčevu monologu istovijeti s Preradovićevim pjesničkim „aktantom“ - putnikom, stanja njegovih dijelova uspoređuju se sa crvenom Marseljezom, Ikarov pad ironizira se zemnom njegovom spolnom potencijom, a putnikovo lutanje s toposom masturbantskog cilja. Grafička izvedba pjesme i varijacije pripjeva izravno, i svakako namjerno, podsjećaju na neke elegije Nikoli Poliću dragog srpskog pjesnika Vojislava Ilića, ali ne samo njega, stilski je, ali i u „narativnosti“, blizak i V. Vidriću, ali i Kranjčeviću, možda njemu najviše. Zapravo je Nikola Polić od stilskih i grafičkih toposa onodobno visoko cijenjene poezije napravio onanistički relata refero, da

25 Usp. podrubak br. 6.

${ }^{26}$ Najvjerojatnije se S. odnosi na Sušak, ali je moguće da je S. i Samobor kamo je N. Polić odlazio k bratu Vladimiru.

27 N. Polić, Pjesme, ICR, Rijeka 1991., str. 279-281. Potpuni naslovi tih pjesama su: SUŠAK/kr. i sl. grad; Sonet s repom / PROTEST / nekolikijeh građana / novopečenoga velegrada; JAO! JAO! / jadna jedna jadikovka / jadranskog Jugoslavena.

${ }^{28}$ Ne zaboravimo da u veljači 1920. godine dolazi u Rijeci do prožimanja futurizma i danuncijanizma, a 11. srpnja 1919. godine Mussolini i Marinetti drže javne govore protiv američkoga predsjednika Wilsona. Među riječkim legionarima u toku sante entrade su i Ricciotto Canudo (1877. - 1923.) te Mario Carli (1888. - 1935.). Ricciotto Canudo živio je u Parizu kao avangardist, pobornik kubizma i futurizma. U Rijeku dolazi u veljači 1920. godine kao predsjednik Fédération des volontaires étrangers, dakle baš u vrijeme kada Nikola Polić piše dvije onanističke pjesme, a malo potom i tri satirične, što, dakako, ne mora značiti ama baš ništa za Polićevo šporkopisanje, ali bi na njegovu domoljubnu pjesničku satiru i bunt D'Annunzijevo zaposjedanje Rijeke moglo biti itekakav poticaj. 
bi šporkom sadržaju priskrbio dostojanstven ornatus po svim pravilima poetske struke, a u dosluhu s vlastitim pjesničkim ukusom. Nije li, na kraju krajeva, rečene pjesnike isticao kao svoje književne miljenike.

Ako se bolje pogleda u onodobne časopise mladih literata, estetska provedba Nikice Polića, bez obzira na namjerno, ili čak nenamjerno, topiziranje, onda su dvije onanističke njegove pjesme u boljem prosjeku tadašnje hrvatske mlade lirike. Štoviše, i zanimljivije su, jer mu estetski učinci nisu bili primarni, a polučio ih je. Ima u njima i od tadašnje mlade garde hrvatskih pjesnika ponešto hinjenog patosa „teška života“, kao i protežnost „lirske boleštine“, koja u N. Polića djeluje kao satirički žalac, baš kao i u spominjanim trima političkim pjesmama-satirama. Dakle „neukusna“ je tema izvedena recentnim poetskim ukusom, kako se to kaže, svoga vremena, Polićeva vremena 20-ih godina prošloga stoljeća, a to je sasvim dostatno za poetsku svijest i u nepretencioznoj nakani.

U drugoj pjesmi, Sveti Alojzije pred Madonom, nalazimo malo drugačiji predmetnotematski fon, čak ima i blasfemije naspram vjerskih predodžaba, ali je i ona sva u hrvatskoj poeziji.

Taj Polićev sonet bez dvojbe ima svoje inspirativno poetičko podrijetlo u Vidrićevoj pjesmi Gonzaga. Budući da su Vidrićeve pjesme bile dobro znane, sušački je pjesnik time osigurao poetičku receptivnost. Osim toga, u Vidrićevu poetskom narativu oslanja se na onaj trentak kada se Sv. Alojziju Gonzagi nudi „noćna kći“, a on je svetački odbija. Slijedi intervencija ganuta anđela i njegove dvosmislene riječi: Prečasni, stani, / I koji su mnogo ljubili. / I oni su Bogu zvani. ${ }^{29}$, nakon kojih slijede stihovi koji se mogu tumačiti dvosmisleno: je li Sv. Alojzije noćnu kći priveo Bogu, ili pak i Njemu i sebi. Narativno je rješenje u dva posljednja stiha Vidrićeve pjesme Gonzaga, koji glase: Baš tako ga vidjeh slikana / U ruci usidjelice ${ }^{30}$. Zapravo pjesnik sasvim slobodno dopušta receptoru da se ironično poistovijeti s usidjelicom i „pročita“ joj misli kako hoće, odnosno da dade odgovor po vlastitu nahođenju.

Ta Vidrićeva pjesma, smatra Nikola Polić, ispjevana je u ironijskom hajneovskom ritmu ${ }^{31}$, pa nam je i to interpretativna podrška, jer je osim sadržaja ponuđen i ugođaj, ovaj put ironični otklon od kanoniziranih predodžaba svetaca. Takva poetička situacija iz Gonzage bila je šlagvort N. Poliću, ali dok je Vidrićeva pjesma lagano pornolagnijska, Polićev sonet Sveti Alojzije pred Madonom nedvojbeno je onaničan kao i Kurčev monolog. Oslanja se sušački pjesnik i na, svojedobno u optjecaju, usmene rimarene pikanterije o nekim svecima i njihovu spolnom životu.

\footnotetext{
${ }^{29}$ Vladimir Vidrić, Pjesme, MH, Zagreb 1963., str. 44.

${ }^{30}$ o. c., str. 45.

${ }^{31}$ N. Polić, Iskopine, o. c. str. 37.
} 
Religijski se sonet Sveti Alojzije pred Madonom donekle može shvatiti i kao sprdnja sa svetim. Tu se, naime, poistovjećuje onanija s molitvom, a Madona je ta koja Sv. Alojziju ima uslišati molitvene želje za orgazmom, jer je ona u povijesti i kroz poeziju, ona koja svakome ispunjava želje. Osim toga, Sv. Alojzije je - masturbant. Životopis Alojzija Gonzage i ono što ga čini nebesnim i nebeskim, ali posve nerealnim ${ }^{32}$ pruža viševrsnu izvedbenu priliku literarnom tekstu ili usmenom stvaralaštvu. Od simbolike koja okružuje Sv. Alojzija Nikola Polić uzima tu životopisnu nerealnost, pa je to u njegovoj pjesmi ljiljan. On je u svečevu legendariju simbol djevičanske Alojzijeve čistoće, a naš pjesnik presimbolizira ljiljan usporedivši ga sa svečevim penisom.

Toliko bi moglo biti ono nužno o predmetnotematskome u dvjema onanističkim pjesmama Nikole Polića. Možemo se pitati kako to da je naš pjesnik, a u skladu sa svojim poetološkim nazorima, odabrao onaniju, a ne koitalnost ili, opću, karnalnost. Držim da je odgovor u prividnu nerazmjeru, odnosno suprotnosti između teme (onanija) i forme (naznačeni poetski poticaji). Tako se nedostatak koitalnosti, karnalnoga, i sadržaja tome slična, poklapa s formalnom sputanošću i općom idejom o određenoj galantnosti poezije. Oboje je, naime, prohodno i suzdržano, rekao bih nedostatno za smjelije porno-zahvate, ne samo za N. Polića nego i za njegovu cijelu grabancijašku svitu. Zato dolazim do metametričkih impulsa, po kojima je, u S. Petrovića, već i sam odabir forme znak koji se ornatno, ili slično, može nasloniti na sadržajno, odnosno - postaje dio sadržaja.

Slučaj s dvjema pjesmama Nikole Polića očit je primjer toga. I „tehnika“ mu je tome primjerena. Kurčev monolog pisan je dvostisima s parnom rimom i promjenjivim varijablama refrenskih, kraćih dvostihova. Duži su dvostisi četrnaesterci, a refrenski kombiniraju onomatopejski troslog s petercem u drugome stihu. Ti duži dvostisi pisani su za hrvatsku versifikaciju relativno rijetkim četrnaestercem, koji podsjećaju na neka drugačija Kranjčevićeva ostvarenja, pa Polićeva pjesma ima i tu parodičnu narav.

Pjesma o sv. Alojziju sonet je s raznolikim dužinama stihova, s rimom: abab abab aba cbc, odiše tipičnim matoševskim, odnosno gričanskim ugođajima, koji nameću i topos takve poetičke naravi.

Dvije porno-pjesme Nikole Polića, bez obzira na sadržajni „iskorak“ sasvim se uklapaju u njegov poetski svjetonazor. Te pjesme ne bismo trebali tretirati kao iznimku u formi, ali u temi svakako, a time je on dao prinos ne samo kućnom Ex librisu eroticisu nego i oskudnom pornosu hrvatskoga Parnasa.

${ }^{32}$ Leksikon ikonografije, liturgike i simbolike zapadnog kršćanstva, Kršćanska sadašnjost, Zagreb 1990., str. 110. 


\section{POPIS LITERATURE}

Badurina 1990

Anđelko Badurina (ur.), Leksikon ikonografije, liturgike i simbolike zapadnog kršćanstva, Kršćanska sadašnjost, Zagreb 1990.

Crnković 1991

Milan Crnković, Poezija Nikole Polića, u: N. Polić, Pjesme, ICR, Rijeka 1991.

Milanja 2008

Cvjetko Milanja, Hrvatsko pjesništvo 1900.-1950. Novosimbolizam. Dijalektalno pjesništvo, Jerkić tiskara, Zagreb 2008., str. 84-96.

Petris 1951

Hijacint Petris, „Nikola Polić“, u: N. Polić, Pjesme, Zora, Zagreb 1951., str. 153-160.

Polić 1953

Nikola Polić, „Pro domo.

Genealogija jedne, u ovom slučaju moje lirike", Republika 6/1953., str. 510-519.
Polić 1959

Nikola Polić, „Sjećanja i zbivanja. Drugi boravak u Zagrebu (19201922)“, u: Riječka revija 3-4/1959., str. 187-201.

Polić 1991

Nikola Polić, Pjesme, ICR, Rijeka 1991.

Polić 2000

Nikola Polić, „Iskopine“, u: J. P.

Kamov, Pjesme, novele i lakrdije, ICR, Rijeka 2000., str. 9-10, 37.

Vidrić 1963

Vladimir Vidrić, Pjesme, $\mathrm{MH}$, Zagreb 1963.

Wiesner 1936

Ljubo Wiesner, „Predgovor“, u: Nikola Polić, Jučerašnji grad, Društvo mladih književnika, Zagreb 1936.

\section{SAŽETAK}

Ovaj rad govori o dvjema pornografskim pjesmama Nikole Polića, koje se nalaze u njegovoj ostavštini. Te se pjesme promatraju u sklopu pjesničkih Polićevih nazora i u odnosu na njegov ostali pjesnički opus.

\section{SUMMARY}

\section{Home porns by Nikola Polić (Ex libris eroticis by brothers Polić)}

This paper deals with two pornographic poems by Nikola Polić, contained in his legacy. These songs are observed within the poetic of Polić views and in relation to his other poetic work.

Keywords: poetry by Nikola Polić, pornographic songs, Croatian poetry 